\title{
Reading Educational Reform with Actor Network Theory: fluid spaces, otherings, and ambivalences
}

\begin{abstract}
In considering two extended examples of educational reform efforts, this discussion traces relations that become visible through analytic approaches associated with actor-network theory (ANT). The strategy here is to present multiple readings of the two examples. The first reading adopts an ANT approach to follow ways that all actors - human and non-human entities, including the entity that is taken to be 'educational reform' - are performed into being through the play of linkages among heterogeneous elements. Then, further readings focus not only on the material practices that become enacted and distributed, but also on the otherings that occur: the various fluid spaces and ambivalent belongings that create actor-network(s) but also escape them. For educational research, particularly in educational reform and policy, it is argued that ANT analyses are particularly useful to examine the complex enactments in these dynamics. That is, ANT can illuminate movements of ordering and disordering that occur through minute socio-material connections in educational interventions. ANT readings also can discern, within these attempts to order people and practices, the spaces of flux and instability that enable and protect alternate possibilities.
\end{abstract}

\section{Introduction}

A recent conference that gathered leading scholars in sociology, human geography, phenomenology, cultural studies and anthropology declared a growing central interest across social science disciplines in the analytical category of 'material practice': 'the move now is to explain the emergence and experience of 'things". 1' In analysing educational reform processes, what insights may be yielded, and what challenges encountered, when we focus on material practices, the politics they produce, and how they are entwined with agendas for educational change? One theoretical approach or 'sensibility' to a socio-material analysis is offered by actornetwork theory (ANT), which has proliferated in the broad field of organizational studies and organizational change since the 1980s. In its early and enthusiastic iterations, as later critics pointed out, ANT tended to focus on the most powerful actors, to imply that all phenomena could be folded into a network ontology, and to overlook the location and gaze of the ANT analysis itself. Certain analytic constructs that emerged from the fine-grained early-ANT studies (e.g. Latour, 1996) also tended to be taken up in ways that eventually became formulaic. Later, reflexive re-thinkings of ANT such as Law and Hassard's Actor Network Theory and After (1999) pointed to the flowering of what is sometimes referred to as 'after-ANT' approaches: a wide-ranging diffusion of rich analyses that continued to trace how things become enacted through messy linkages among human and non-human elements, and to explore networks within networks, but which also honour multiple ontologies, ambivalences, and modes of enactment. Given this wide diversity, and given analysts' own care to distance themselves from any identifiable ANT orthodoxy or method, it seems safest to refer to a reading inspired by ANT approaches as 'ANT-ish' - which is the cautious if perhaps inelegant signifier adopted here.

But aside from a few accounts of educational innovation and policy drawing upon ANT (see Fenwick and Edwards, 2010 forthcoming), educational change literature in the main offers little

\footnotetext{
${ }^{1}$ Materialising the Subject: phenomenological and post-ANT objects in the social sciences, University of Manchester, Feb 26-27 2009, http://www.cresc.ac.uk/events/forum/MaterialisingtheSubject.html
} 
uptake of ANT concepts and the wider diffusion of after-ANT questions about ontological politics, otherness and mobilities. Yet these ANT inquiries into material practice, with their network readings that radically reconfigure human/nonhuman interconnections, would appear to offer useful engagements for debates in educational reform.

This discussion works from ANT-ish (including ANT and 'after-ANT') concepts and two extended examples of educational reforms to address the question: What does a network analysis contribute to understanding educational reform efforts? And to turn this question on its head while remaining within ANT-ish logic of radical relationality, translation and sociomaterial hetereogeneity about which more will be said later, the discussion considers: What can be understood about educational reform by stepping outside a network analysis, which while important for illuminating certain dynamics, can become a singular and totalizing representation that obscures others? In other words, how might after-ANT readings of educational reform help us to appreciate the spaces or blanks beyond networks, the partial and ambivalent belongings, and the otherness that cannot/should not be colonized by a single (networked) account? The argument ensuing from these questions suggests not only that ANT-ish readings open helpful questions for researching educational reform, but also that an educational consideration suggests useful spaces for the ongoing development of material semiotics and other after-ANT explorations.

\section{ANT, After-ANT, and Educational Reform}

Educational reform projects typically are premised on a functional logic of implementation and measurement - usually directed towards changing pedagogy and other school structures in ways that will increase student achievement. Thus it is also an expensive, politically visible and complex enterprise that can attract close scrutiny of the public and a range of suspicious engagements from educators and educational administrators. Before examining what ANT might offer, it is important to acknowledge the different kinds of questions attracting inquiry into educational reform. One kind are critical questions about hegemonic reform purposes, the warring interests, agendas and exclusions embodied in certain state-initiated reform efforts (Taylor 2002), and the oppressive regulatory effects on life in schools and teaching-learning processes. While important, these tend to focus solely on the social rather than the sociomaterial, and are based on a priori assumptions about social structures and subject categories that ANT readings call into question. A second kind are questions around the processes themselves of educational reform: how does it work over time and place, how do different actors respond, what rhetorical and material struggles ensue, and what actually changes? Volumes of educational change literature have addressed this problem. Conceptions borrowed from organizational studies range from episodic event-oriented transformation to incremental process-based recursive change (Weick and Quinn, 1999). Reform processes range from various iterations of strategic planning (preliminary explicit goals, stages of planned implementation including management of resistance, evaluated outcomes) to epidemiological diffusion (innovation is dropped into the container of the environment and gradually spreads through incentives and social processes such as persuasion and knowledge-sharing). Selected notions of complexity theory such as emergence, self-organization, recursion and fluidity adapted for educational managers (e.g. Fullan, 1993) have attracted popular appeal. Related models of the 'professional learning community' (Du Four and Eaker, 1998) centre educational reform at the site of the teacher, 
framing teacher learning as the problem and conventional if ambiguously romantic ideals of knowledge sharing in 'community' as the solution.

But the difficulty with this problematization of change processes in an organization is its starting point of conceiving the classroom, school or school district as distinct homogeneous organizations, and furthermore, organizations that are essentially social. Thus the category of the 'thing' to be changed is established a priori as an entity, separate from the thing that is understood to carry within it the force for change. Furthermore, the emphasis on personal and social processes, as important as these appear to be in constituting the cultural, emotional, political and psychological relations at work in education, completely ignores the material presences that exert force and are entwined with what appears to be human intention, engagement, resistance and change. A second problem, elaborated by Nespor (2003), is the conception of an educational innovation as a seed that is dropped into the pre-existing context of the school or school district. This presents context as a container and innovation as an origin that will grow (to use an arborescent metaphor), spread (to suggest an amorphous diffusion process), or be 'rolled out' (to use common parlance suggesting flattening of school landscapes with a road grader).

What then escapes analysis in the container-seed conception is the actual forms and outcomes of struggle negotiated at each of the myriad nodes of the process - each interaction between human elements (desires, pedagogical knowledge, attachments, intentions, etc) and objects (such as textbooks, lab equipment, assessment forms, policy statements, parent newsletters, databases). Furthermore the diverse ongoing work required to sustain or even to stabilize any new educational change is often overlooked. The conventional story is that after implementation whether it is conceptualized as growth, spread or roll-out - there is institutionalization (Crossan et al. 1999) or, alternatively, failure, and that appears to be the end of the reform tale.

In contrast, Nespor (2002) argues from an ANT-ish approach:

The point is that we need to understand 'school change' as at least partly about the ways school practices are made mobile, and what and how they connect as they move. What are the structures of connections or linkages? What materials are they made of? How do things change as they move? How do connections change with this movement? (pp 367-68)

Actor network theory offers concepts that illuminate dynamics of educational reform often left aside by these more structural or socially-focused analyses - including how actors emerge within the play of heterogeneous linkages among humans and nonhumans, and how the different actors that appear are performed into being by these linkages. As Law (1992) explains:

This, then, is the core of the actor-network approach: a concern with how actors and organizations mobilise, juxtapose and hold together the bits and pieces out of which they are composed; how they are sometimes able to prevent those bits and pieces from following their own inclinations and making off; and how they manage, as a result, to conceal for a time the process of translation itself and so turn a network from a heterogeneous set of bits and pieces each with its own inclinations, into something that passes as a punctualised actor. (p. 386) 
The naturalization of a notion called 'educational reform' can be traced as an actor that was built over time and is now held in place by other actors and chains of ongoing effort. Instead of containers, ANT works from network metaphors to envisage change processes, including what appears to be teacher development and student learning, as the building of networks through all of these linkages. The more extended the network - the more entities that become 'enrolled' into its links and 'translated' or transformed in ways that support its work - the more likely it is to endure over time and to extend across regions. ANT looks closely at the translation process, tracing how an entity, human or nonhuman, becomes selected, enticed, persuaded and partially or fully changed in ways that mobilize it to join the network's movements. Further, ANT examines the various network strategies through which this durability and mobility is achieved, always focusing attention on the tiny, often mundane exchanges going on within the complex commotion of materials and human action that we think of as educational life.

An ANT reading of educational reform offers useful concrete insights about what goes on in the dynamics of change. In the field of organization studies, ANT analyses of innovation and change processes have proliferated to trace failures, showing how networks have imploded or failed to enrol sufficient entities to survive (Latour, 1996, Czarniawska and Hernes, 2005), as well as to examine successes, showing how the networks of 'macro-actors' - large initiatives, associations, bodies of knowledge or practices - have expanded and thrived. After-ANT readings focus on the material practices that become enacted and distributed, but also on the otherings that occur: the fluid spaces and partial belongings that can comprise what appears to be a powerful network (Law, 1999). In education reform, ANT-ish inquiry might ask: How does a new state initiative seeking to generate 'school improvement' produce itself into a 'thing'? How does 'it' (or they, for 'it' may be multiple things) become enacted over time and across different regions? What diverse negotiations and responses are generated through material practices, and how do these affect its durability and force? What exactly becomes engaged and connected, what becomes excluded, and how do these involvements shift over time? Where and how does power accumulate through these negotiations?

Education change literature offers a few ANT-ish analyses that provide in-depth tracings of these dynamics often obscured in considering educational reform. In the sections that follow, specific examples of these analyses are offered to show the fecundity and flexibility of ANT readings in studying educational reform. First, the different ANT approaches to network readings are introduced in the context of education. Second, an extended example is described of a study of university reform using a basic ANT network reading. Third, the after-ANT considerations of such a reading are described in more detail. In the fourth and fifth sections, an example of a large provincial reform in public education is presented to show how both ANT and after-ANT readings can be employed to glimpse critical dynamics of the reform process in its many spaces and ambivalences.

\section{Network Readings and Educational Reform}

Jan Nespor $(1994,2002)$ was one of the first educational researchers to employ ANT-associated network readings to analyse educational processes and reforms. In doing so, Nespor carefully distinguishes this approach from that of social network analysis, which treats actors as welldefined entities pre-existing their social relations, and network ties as static and neutral. Instead, Nespor treats networks as assemblages of heterogeneous entities such as written curricula, 
videos, human actions and buildings that can move educational practices across space and time (2002 p. 369). Entities themselves are neither solid objects and subjects nor clearly separated from their context. They are each an effect produced through a set of relations that is constantly in motion. The network that appears through the linkages among these entities is a trace, reasonably stable, of a series of translations that have changed and continue to change each entity participating within the network. In fact, network effects work on and are exercised by entities that may not be enrolled into a particular network.

However in education, Nespor (1994) argues that ANT's tendency to focus on powerful central actors does not particularly improve understandings of those at the margins - most obviously and importantly, students - whose identity and action is tied up with being mobilized. Furthermore, if ANT readings focus on a network's centre, the observer might be captured by the appearance of flow from every direction which misses the entrenchments and stable divisions that are more visible 'from a distance'. In education, these "deeply worn channels" (1994, p. 15) formed by particularly durable networks such as racism and colonialism - not to be confused with anterior conceptions of 'social structures' - are critically important to analysis. But far from abandoning ANT for education, Nespor (1994) concludes that its frames help illuminate the "structure of networks, the ties that bind them, and the nature of whatever it is that flows through them" (p. 23). Furthermore, ANT readings can show precisely how educational innovations and practices order space and time as well as forms of participation in networks of power. That is, ANT penetrates the different sociomaterial negotiations occurring in the evolution, extension and sedimentation of these networks that appear to discipline people and knowledge as well as technology and the natural world so effectively.

Important critiques of the network metaphor (Bloomfield and Verdubakis 1999; Hassard, Law and Lee 1999; Lee and Brown 1994) have pointed out that it appears to totalize reality, implying that all possible elements, entities and imminences are accounted for and securely positioned within network(s). Annemarie Mol and John Law (1994) are among those who have conceptualized other ontologies alongside networks, such as fluid regions or ambiguous, emergent spaces and relations. One can imagine multiple network forms and intensities whose very multiplicity of shifting interactions creates fluid improvisational spaces. Despite some unfortunate metaphorical baggage of networks as self-contained linear pipelines or reified engineered linkages, networks can be envisioned as far more ephemeral and rhizomatic in nature. Networks are simply webs that grow through connections. The connections can be thick and thin, rigid and limp, close and distant, dyadic and multiple, material and immaterial. And the connections have spaces between them. Barbara Czarniawska and Hernes (2005) propose that we think of action nets rather than networks to avoid the sense of inevitability and lock-down that 'network' seems to imply for some. But for the purposes of this discussion, the word 'network' will be used. This is intended to invoke the simple but plastic concept of an unspecified set of connected points or nodes with un-represented spaces among them. The word also serves as a useful reminder both of the precariousness and unpredictability of any network's formation and continuity, as well as the multiple shapes and lengths it can assume - from a large open fishing net to a tightly clasped net bag, from a sticky and multi-netted local web to a far-reaching network gathering global industries into some standardized practice.

In terms of educational reform, Nespor (2002) argues that a network reading shifts the tendency 
to view certain participants as 'reformers' and others as 'contexts', to understanding that all are part of materially heterogeneous networks that have unfolded geographically and historically and that overlap and relate with one another. Reforms and contexts mutually create one another. Reforms are "contingent effects of struggles and negotiations in which groups try to define themselves and their interests by linking up with other relatively durable and extensive networks" (Nespor 2002, p. 366). Elements that appear to lie outside a school's networked activity, such as a parent for example, are in fact connected to and partly produced by it. For example, Nespor shows how the school's network of reform extends into a parent's actions and identity through a child's homework. The homework was treated by the parent not just as an object of performance circulating within the school, but as a comparator to the child's homework produced years earlier. Then this representation was 'hybridized' with terms of the national curricula debates, which 're-territorialized the homework' and re-scaled the local school into part of the national problem, while translating national-level debates into specific critiques of the local school reform. The mother doesn't just participate in the school reform but actively reframes it into terms that she can oppose. For Nespor, the important questions for educational reform that can be illuminated through such network readings include "how and in what forms people, representations and artifacts move, how they are combined, where they get accumulated, and what happens when they are hooked up with other networks already in motion" (pp.376).

\section{A First Reading of Reform: Extending the Network}

One study that explores these questions in educational change using an early ANT concept will be described in some detail to show more precisely what a network reading might reveal. Jo Ann Luck (2008) examined the processes of implementing a video-conferencing system in an educational institution, Central Queensland University in Australia (CQU). Working with Callon's (1986) original 'moments of translation' (problematization, interessement, enrolment and mobilization), and treading carefully to avoid reifying a particular analytic model and colonizing the reform landscapes to fits its precepts, Luck offers useful insights about the ways in which a new network of usage grows. She traces how the network moves in education among highly diverse groups of actors - faculties, support staff, facilities and students - distributed across diverse regional sites and already enrolled in durable networks of teaching-learning practices. This analysis is particularly useful for, as Busch (1997) has argued, university knowledge disciplines and practices are heavily 'blackboxed' and particularly resistant to new translations. Using an ANT analysis, Busch argued that universities consist of highly durable actor-networks held in place by linkages among vast networks of equipment, architectures, other institutions, and historical relational patterns.

The CQU reform process began with certain activities at the university level (videoconferencing trials, forming a steering group, writing a grant) that created loose local networks. These local networks aligned with national networks pressuring for reduced spending, increased student access and a unified national system in higher education in ways that not only granted these more distant networks material presence and strength in the university, but helped to strengthen the local networks. Luck also shows the importance, perhaps particularly in hierarchical institutions such as higher education, of a 'heterogeneous engineer' who exerts sufficient authority to define the 'problem' in ways that other actors will accept. In the CQU case, Luck presents the university's senior management as this engineer. However, a simple decree from managers rarely accomplishes implementation. In this case, a 'Future Directions' document circulated by senior 
management problematized existing teaching-learning systems and convincingly linked these with the funding and viability problems of the institution. This document became a key intermediary - an actor that can translate thinking and behavior - in the form of an 'immutable mobile', an inscription that itself represents a translation of a series of events and actors and that has achieved sufficient durability to circulate across far-reaching space-times.

This document combined with various objects to problematize existing practice and begin a process that Callon called 'interessement' - where one actor, human or nonhuman, influences and attempts to join with another in order to enrol its participation in a new network. These objects included, for example:

- a logo - 'Vision 97' for the initiative,

- grants made available to install the new interactive video-communication (IVC) systems in classrooms,

- letters sent to students and parents guaranteeing that they could complete a degree at home and avoid relocation costs,

- $\quad$ prospective promotions for support staff involved in implementation, and

- demonstrations of the higher quality and convenience of the proposed IVC systems comparative to existing temporary cabinets rolled from room to room.

As Luck notes, once there are rooms, screens, wires, microphones, policies and training schemes in place, "[the IVC implementation] is more credible and compelling as a useful system for performing teaching activities" (p.181). The active circulation of these objects throughout CQU's distributed sites occurred not only through mail, media and announcements, but also through establishment of a 'walking group'. This group visited all constituents in all regional campuses to engage them directly in the initiative, talking about and touching components of the IVC. Luck's analysis shows how what goes on at these different nodes of circulating objects and humans - the attempts to translate through problematizing, persuading and enrolling at the farflung edges of the network's potential reach - actually builds the new network of practice bit by bit.

Actors' enrolment in the network is, however, precarious, and needs to be stabilized if the network is to endure. Luck shows the multiple negotiations that continued to occur throughout the network to inscribe the various actors into certain roles that became glued together in a configuration that could perform the new IVC teaching-learning system. Much of this negotiation was at the linkages of objects and technologies with human intentions, expectations, and attempted actions. Each of these linkages embedded endless numbers of artefacts, mediators, and inscriptions negotiating connections that gradually became locked into the new network. For example, sound issues of the new system entailed speakers and speaker adjustments, recordings, variable control panels, refinements to microphone size and links to manage the unique classroom demands on the IVC, carpet installation to address noise concerns, technicians, designers, trials, written concerns about cost escalations, and so forth.

Luck's study in effect traces the various forms of ordering that can hold precarious relationship in place, as described by Law (2003). Durability, which is ordering through time, can be achieved by 'delegation' to the most durable materials that can maintain their relational patterns, and to other networks to hold in place these durable materials (technicians and repair agencies 
hold microphones in place). Mobility, which is ordering through space, can be achieved through what Latour called 'immutable mobiles' that travel, binding various locales into central modes of calculation. Centres of calculation and translation order direction, voice and representation, often by anticipating the responses and reactions of the materials to be translated. And finally the scope of ordering is extended when strategies of translation are reproduced in a range of network locations.

Overall Luck's network reading helps illustrate how, in educational initiatives of innovation and reform, insufficient attention is often granted to the active role of objects and technology. These tend to be treated as brute things to be installed rather than dynamic actors. To grow a network, relationships need to be built carefully and flexibly among the mix of objects-technologieshumans, attuning to nonhuman actors' capacity to act back in ways that network engineers may not have anticipated. Luck points out various strategies through which a fragile new network of these relationships is extended and strengthened in a successful educational reform. For example, 'key' actors are employed as intermediaries, as many actors are added as possible, and alignments are made with other, distal networks such as national priorities and international discourses in education. Such strategies contribute to the extension, durability and even irreversibility of a new network, with perhaps undesired forms of entrenchment. But the network is also experiencing continual challenges and shifts at its multiple micro-connections as actors discover and exploit weaknesses in inscriptions, or enact 'anti-programs'. Constant attunement to these shifts and flexible adjustment is the essential everyday work of those actors interested in sustaining a network of educational reform. The work is ongoing not only at these nodes but also in the overall shape of the educational institution as the new networks stretch and translate its appearance, its functions, and its extensions into spaces that appear to lie beyond it.

\section{Re-thinking the Reading: Centrality and Otherness}

Luck's (2008) analysis of educational reform employs an early-ANT model to trace the ongoing, unpredictable, often difficult socio-material transactions at a micro-level. While useful, this model is not without its critics who have pointed out several cautions for researchers. One is the tendency for any theoretical approach like this to become sedimented into an explanatory frame that is imposed, a priori, on the data. This is especially problematic for ANT, which has striven to maintain a fluid, decentred and exploratory approach that challenges a priori concepts and structures and honours complexities of immanent, emergent phenomena. However in response, McLean and Hassard (2008) argue that the four-stage model can be viewed more as a heuristic or 'sensitizing' concept adapted to make sense of complex observations. Analysts of educational reform need not not slavishly impose four steps and expect a linear process, but appreciate that translation is ongoing, iterative and disorderly.

Two further critiques of 'early-ANT' applied to educational reform involve the problems of centrality or focus on 'big actors', and the problem of difference or otherness. The issue of centrality emerged when so many ANT studies focused on the development of large, powerful networks such as major policy initiatives. While ANT concepts are clearly helpful in illuminating the movements resulting in success - or failure, depending on the perspective and interests of those judging - of a major reform, the danger is lack of reflexivity about what the analyst is including and excluding. As Strathern (1996) points out, the ANT decision to 'cut the network', to establish boundaries around the object of inquiry, is problematic if it simply adopts 
the categories of its subjects and focus on what appears to be most important and visible. This was Nespor's (1994) difficulty with ANT applied to education in ways that focused on big projects and ignored those with less visibility, fewer strategies or complex relations to networks. This issue opens out to a whole series of questions about otherness in ANT, which Hetherington and Law (2000) summarized in a special journal issue devoted to the topic. They argued that the metaphor of the network can presume to colonize all dimensions, elements, layers and spaces of a phenomenon, as though everything that exists is drawn somewhere, somehow, into the relentless knots of networks extending infinitely. A network reading potentially "leaves no room for alterity and allows for nothing to stand outside the relations that it orders through its descriptions of the word" (Hetherington and Law, 2000, p. 128). This problem extends further than colonizing or 'speaking for' not only marginalized humans but also marginalized objects. The problem is also about dividing space and action according to issues of relation and difference: what becomes connected and mobilized into a network and what remains different according to that network's terms and relations. What of alterity that is blank, unexpected, novel and ambivalent? What of otherness that lies within or flows across network alignments, that is incoherent or non-representable? These questions warn the ANT-reading from presuming to offer any single account of events, and alert attention to spaces and discontinuities that may be distorted through a conventional network reading.

However, as Julia Clarke (2002) has argued in her analysis of a major literacy policy initiative in the UK, education continues to struggle with 'big actor' reforms that do threaten to enrol wider constituents, including critically challenging actors and counter-networks of resistance, sedimenting all of these heterogeneous elements into powerful networks that can function oppressively. ANT analysis is particularly useful in tracing these power relations, showing how connections and translations among materials as well as language and social processes can appear to lock hegemonies into place. Clearly ANT-readings need to move as carefully and reflexively as possible, mindful of their own tendency to create obligatory points of passage, cautious in neither totalizing nor ignoring phenomena unfolding, and mindful of both their own highly provisional accounts and the entanglement of these accounts in constituting the phenomena being read. But limitations of gaze, as in all forms of research, are matters of caveat, not censure for a particular theoretical approach such as ANT.

\section{A Second Reading: Mobilizing and Sustaining Reform}

Let us consider another example of an educational reform launched in 2000 in Alberta, Canada and still thriving, rather astonishingly given some of its precepts, at the time of writing 9 years later. Why? How? In the following ANT-ish reading, based on reports of the project rather than empirical tracings ${ }^{2}$, certain concepts appear useful to go some way to address these questions. ANT helps illuminate moments in the enrolment and translation of actors, the importance of particular mobile inscriptions that travel about ordering particular activities, the problematization and relations that establish centres of calculation and translation, and the overall gradual assemblage and strengthening of a network through various strategies. But the case also resists an overly tight emphasis on network-building, for non-networkable spaces and otherness can be glimpsed when we probe what is going on in the unfoldings of this network. Indeed, certain otherings appear in some ways to be enabling the most visible network to proceed with its work.

\footnotetext{
2 Documents examined include government reports and papers, a database containing 1200 individual school project reports, theses and scholarly research publications examining aspects of this reform project.
} 
The following account is not intended to collapse this complexity into a glib performance of (otherness-enriched) network reading, but to suggest the potential for ANT-ish approaches to not only analyse how powerful networks become set in motion through educational reform but also to gesture towards gaps and more fluid spaces within and among these networks. The case is an educational reform called the 'Alberta Initiative for School Improvement' (AISI) that states its official goal as being "to improve student learning and performance by fostering initiatives that reflect the unique needs and circumstances of each school authority" (Alberta Learning, $1999 \mathrm{p}$. 4). The initiative has made available Alberta government funds to any school or school district whose proposal for a 3-year school improvement project is judged by the provincial ministry, Alberta Education, to be acceptable according to clearly communicated criteria - particularly the criterion to improve student achievement, mostly through measurement on provincial standardized tests ${ }^{3}$. The first 3-year AISI period or 'cycle' supposedly showed such general success in improving student test scores and meeting individual projects' student achievement targets, according to government reports (Alberta Learning, 2004), that AISI was renewed for two more 3-year cycles since start-up.

The initiative is characterized by several features that are surprising in a context where bitter disputes between the government, school districts and teachers marked the 6 years of educational restructuring for accountability prior to 2000 (Taylor, 2002), when districts were amalgamated, standardized student testing expanded, and business planning introduced in a "wave of top-down, seemingly ideologically driven package of educational reforms" (Berger et al., 2001, para 12). Perhaps the most surprising feature is the vast number of schools and districts that became involved and continued their involvement in the AISI reform, despite the recent history of stormy relations. A second point of interest is that AISI established a partnership of the government with all educational professional associations, an alliance whose sustainability over 9 years is worth noting given the rather wide range of ideology and interests represented by these organizations ${ }^{4}$. Third, the government has committed more funds to AISI than to any other educational reform and further, in an historically unusual arrangement, grants these funds directly to school districts. Approximately $\$ 500$ million CAD to date has been committed to fund projects in about 1600 schools (of Alberta's 2246 total number of schools) (McEwan, 2008). Finally, AISI has managed to actively involve university faculties of education in its projects, despite broad areas where philosophical contestation and resistance might normally be expected. For example, the current AISI website, an exhaustive collection of individual project reports, province-wide meta-analyses and AISI histories, databases of 'lessons learned' in every curricular area etc., liberally foregrounds concepts such as 'evidence-based' education, universalized 'best practices' of pedagogy, and classroom-based research limited to improving teacher techniques towards outcomes-based student achievement.

\footnotetext{
${ }^{3}$ To be approved, the project proposals not only must be clearly organized with literature reviews, budgets, project plans, methods and 'improvement goals aligned with strategies and measures', but also must show baseline and improvement targets, ongoing administrative support, a project coordinator, knowledge dissemination plan, and community/parent involvement (McEwan 2008 p. 5).

${ }^{4}$ Six organizations developed the AISI in 1999-2000: Alberta Education, Alberta Home and School Councils' Association (AHSCA), Alberta School Boards Association (ASBA), Alberta Teachers' Association (ATA), Association of School Business Officials of Alberta (ASBOA), and College of Alberta School Superintendents (CASS). In 2000, University Faculties of Education (Alberta, Calgary, Lethbridge) were also invited to join the partnership.
} 
So the question of how AISI managed to extend as far as it did, enrolling and sustaining participation among such diverse constituents, is of particular interest. A network reading could show the importance of intermediaries, like money, in attracting participants. Superintendents for example, after a decade of funding cutbacks and restructuring, were highly motivated by the offer of cash for improvement proposals even when they were aware of their own 'translation' in accepting the grants. One superintendent explained:

The name of the game is conditional granting. They call it enveloping or whatever terminology you want, but it works . . . because it creates the behaviour you want. In my instance for example, AISI [Alberta Initiative for School Improvement] money, politically I can't afford to let over a million dollars go. I would get crucified . . . by my board, by our parents, because we let a million dollars slide. They don't care what has to happen to make it happen, just get it for us. . . They say we want you to jump one foot and it works because the carrot is one foot off the ground. (Berger et al., 2001)

The attraction for teachers lay at least partly in the apparently open nature of AISI projects. The project problem, content and methods are left entirely to the discretion of the school or district applicant - as long as they can demonstrate an improvement to student achievement. Most early projects were oriented to improving student literacy and mathematics achievement. Other popular areas emerging over the nine years were developing pedagogies for English-as-SecondLanguage instruction, for integrating technology into classrooms and for 'differentiated instruction' (instructional approaches to meet different student special needs and learning styles). In all of these projects, a stream of new materials came rolling into classrooms: class sets of mathematics puzzles and blocks, new computers and teaching software, textbooks and teacher guides. Teachers were intimately enmeshed in putting to work not only these student materials, but also the new instruments of data collection that each project needed to design.

Once districts and teachers were mobilized to design and apply for projects for which they had local affection and commitment, intermediaries began to circulate around the province that helped translate these energies into certain consistent practices. The project proposals, for example, demanded structures of pre-and post-project measurement of student performance, as well as a research design. Each project also was required to produce an annual report according to a template created by the government AISI office, a report that focused attention on technical information such as improvement objectives, key strategies, evaluation methods, student outcomes, effective practices, sustainability, what worked and what didn't work, etc. (Alberta Education, 2008), with little space for exploring or recognizing complexity. These reports are all posted publicly on a searchable web-based database, an inscription which collapses, orders and translates complex multiplicity into one centre of calculation. Other centers draw together the nodes of the projects to further reinforce the network. A province-wide AISI conference sponsored annually by the province features presentations from teachers leading the projects. AISI coordinators, known as 'lead' teachers with credibility in their district, are trained for the role and gathered together throughout the year for support. Now appointed in $74 \%$ of Alberta districts, these individuals represent more intense nodes of translation spreading throughout the extending network.

The concept of 'translation' in large-scale reform implementation reaches beyond the 
conventional considerations of change theory for actors' personal attitudes or levels of adoption, their social ability to interpret and integrate (Crossan et al. 1999), or their capacity to shift institutional structures. Translation examines how, in the process of implementation, relationships with things actually become transmuted. Textbooks and plastic blocks and computer games became objects of study. Lesson plans became experiments. Everyday interactions with students became 'benchmarking'. Student assignments became AISI findings. In other words, the translation of teacher to (AISI) researcher fundamentally changes the pedagogic gaze, identity, and relationships.

As all of these practitioners struggled to develop project proposals and final reports, indeed to reconceptualize classroom work as an AISI project, the province's six universities were mobilized to assist schools with meeting the research requirements. Each was allotted sufficient funds to appoint its own AISI coordinator and office, which began generating websites about classroom research methods and distributing materials such as measurement tools in workshops and school visits to show teachers how to collect and analyze their own data, 'benchmark' student achievement, etc. In each of these moves, an ANT-reading of available documents illuminates how the reform spread not through top-down imposition but through circulation - of inscriptions, intermediaries, collaborations with objects and technologies, and a host of actors translating one another, assembling highly heterogeneous institutions, political interests, philosophies of knowledge and suspicions about reform.

A network is strengthened when it becomes linked with other existing actor-networks. In the AISI case, other networks besides the universities became hooked in. The provincial teachers' association viewed AISI projects as sites for professional learning communities (PLC), and actively promoted both the AISI Clearinghouse of project reports and lessons learned, and PLC workshops to support AISI projects (Alberta Teachers' Association, 2008).

Clearly AISI appears to have established and extend itself as a far-reaching and durable network. It has mobilized hundreds of teachers and administrators (linked with classroom materials, databases, school timetables and equipment) - as well as universities and professional associations - to accept their own translation into designated roles that extended and stabilized the network. AISI seems to work partly as a mediation between the local networks of schools and districts, and the more extended but distinct networks of the teachers' association, the university's education teaching and research programs, and the government network. Each network maintained its own life and circulations while being bound up, for different reasons and to support different agendas, in the circulating inscriptions and translations of the AISI network. The government coordinator of AISI activities claims that "multiple sources of evidence" show that AISI has had "profound effect on education in Alberta" particularly in "improved student learning, renewed focus on teaching and learning, better decision-making based on evidence, job-embedded professional development, and shared and distributed leadership" (McEwan 2008 p. 6).

\section{Re-reading Reform: Fluid Spaces and Ambivalent Belongings}

However there is much that is obscured by this reading focused on centricity, on how the reform extended and stabilized itself. What beckons some acknowledgment, at least, are the spaces and the otherness shadowed away by the foregrounding of a seemingly immutable 'AISI network' as 
though it were cut into the province like a madly branching river. Different spaces, even different forms of space, can be discerned moving in and around the most visible network of power. Further, there seem to be different forms of belonging to this network and its tributaries. The simple question of how translation occurs does not reach far enough. What about partial translations - when and why do these occur, and how do the resulting ambivalent belongings affect the overall network?

Returning to the teachers who appeared to become so widely engaged in the projects, it might be understandable that these in fact represented a rather open space. While the start and end points were shaped by the prescribed proposal and report templates, and while the objective was predetermined to be student achievement, the freedom to choose the content, activities and materials for the project opened an important space of local innovation and control. In other words, projects were widely diverse in their question as well as their pedagogical content. Some schools worked with the prescribed provincial curricula, and others focused on implementing what might be considered more popular (perhaps even theoretically questionable) initiatives such as 'multiple intelligences'. Teachers try new pedagogical practices, collect data in the classroom evidencing the success of these practices, and report results. The projects are referred to as action research (Parsons et al. 2006), and appear to offer opportunities for teachers to engage creatively in generating and legitimating the classroom-oriented, practice-based knowledge that advocates of teacher research have been promoting in recent decades (e.g. Cochran-Smith and Lytle 1999). Teachers were invited by AISI to become translated into knowledge producers and authorities. In fact the university representatives were translated by AISI into roles that served, rather than disseminated, knowledge production. These local spaces of innovation and discretionary action are critical, argue Bowker and Starr (2000), to maintain network extension by retaining "intimacy in its detailed knowledge of the nuances of practice" (p. 232). Too much standardized control and network imperative threatens its manageability and survival.

These spaces might be seen as the gaps between the network knots, if the knots are simply the visible parts of the project - the required reports - that are calculated and gathered into dense sites. But like a fishnet, big spaces can open where these calculations do not specify type of pedagogies, direction of project, pace of implementation, enrolment of actors, standard instruments or texts, etc. Since the scrutiny of the text focuses most on the measurable student achievement, these spaces exist as an unrepresented other to the network. The actual materials used, the pedagogical approaches tried, the various experiments and failures and upsets, the everyday commotion of classroom action, the wide uses of objects - all of this swirls in a space outside the attention of the network. This other is assumed to be present by the network's reports, but is in fact absent. It escapes representation in an otherness that Law terms 'manifest absence' $(\mathrm{xx})$. Thus, what constitutes an AISI project, the thing that is linked into such an apparently durable network, exists in different dimensions. It exists as the neatly ordered project reports and all the meta-analyses generated by these. It exists as the funded set of materials and activities that teachers and administrators manage and plan. But the AISI project, unbounded, is also the immanent, ineffable events of the classroom reality, which as Thrift (2000) argues, always and necessarily lives outside network space. Perhaps the only central thing holding together the AISI network is the circulating insistence on increasing measurable student achievement. But even this notion appears to slide in the messy spaces of the network. Stelmach (2004) for example, shows that at the level of parent and teacher discussions, impact on achievement was often 
overlooked: AISI project success was explained in rather symbolic terms, and a perception existed that as long as strategies that were implemented during the project had life beyond the three-year project, AISI had succeeded.

For the universities the AISI projects exist as a research enterprise. But fluid spaces open here, too. Approvals for ethical research procedures, for instance, which the university regards as essential in any project that collects and represents data, fell into a space between direct grants from government to schools and university assistance to conduct research (Parsons et al. 2006). Teacher-researcher training, normally conducted by the faculties of education through accredited courses and programs under their control, now was permitted, indeed encouraged, in spaces with no tuition, progression or clear disciplinary authority. In network logic, university personnel were simply enrolled into extensions of knowledge exchange reaching beyond the districts. But in fact, these extensions created fissures that generated complicated spaces where various dimensions had to be negotiated.

These spaces of manifest absence are not concretely visible to AISI's continual translations, although their presence can be circumscribed as inside or outside the network. However beyond these spaces lie other regions, or perhaps other forms of spaces, that a strict network reading of the massive AISI reform and its intersecting networks cannot circumscribe. One of the most obvious of these is the othering of inquiry that reaches outside the a-critical and a-political AISI circumscription of particular forms and questions of research. Everything in AISI is, after all, geared to improving instructional methods for a narrow set of academic student engagements. Only rare projects address students' experiences beyond these engagements, or analyse issues of equity and justice. Few projects explored poverty or health, racism, homophobia, religious discrimination or social exclusion in schools despite the prominence of these issues in the education system. None critically examined educational policy, or analysed systemic politics and power relations in school practices, texts, relations, and so forth. Utterly absent was educational research reflecting post-structuralist, feminist, post-colonialist, or any number of other contemporary and increasingly widespread orientations in university-based educational research. In fact, in one presentation to the Alberta school superintendents association, AISI was claimed to be the "gold standard" of improvement models that sends a "clear message" to universities that the only valid research is that which reflects student achievement results (Reeves 2005 p.15).

However with the universities enrolled in extending and strengthening the AISI network, the appearance is created of scholarly approval and support for the AISI-endorsed form of educational research: that is, research that focuses on measurable improvement to teaching methods to produce measurable improvement in student test scores with no attention to social relations, power and positionality, cultural difference, inequitable structures, systemic problems, undecidability, contradiction or messiness - all the dimensions of critical inquiry that academic educational research has been leading. Further, 'action research' becomes converted to solving pre-determined problems, an AISI formulation that completely ignored Alberta scholars' explorations of classroom action research as participatory, hermeneutic, emancipatory, and emergent (e.g. Carson and Sumara 1997). But were the universities truly enrolled? When we examine their actual involvement, it appears that each of the province's six universities had simply used AISI funds to cover partial salary of one faculty member designated as an AISI coordinator and provide some clerical support. Some, but certainly not all, of these university- 
based AISI offices became active in training teachers and school district AISI coordinators in research methods, and maintaining websites to support AISI research (Parsons et al., 2006). But AISI activity and offices do not appear on the university websites. And surprisingly, given the rich abundance of AISI-sponsored classroom research proceeding around the province, almost no faculty research has been conducted around any aspect of AISI - not even critical analyses, and very few graduate theses. There may be diverse reasons for this indifference - perhaps faculty scholars are deliberately distancing their work from AISI-prescribed projects, or expressing distaste for classroom research and teachers as researchers, or are simply unaware of the possibilities or too busy with competing priorities. Whatever the reasons, the six university faculties of educational research can be described as belonging to the AISI network only as ambivalent members. They have accepted the funds and the attached responsibilities to promote AISI, they have maintained their names as full partners on the AISI website, but the translation of their roles has remained minimal.

Parents, too, were enrolled in ambivalent ways in the AISI network. While AISI projects required active involvement of 'parents and the community to work collaboratively to introduce innovative and creative initiatives' based upon local needs and circumstances (Alberta Learning 1999), there was general agreement that parent engagement in AISI projects was peripheral, relegated to receiving special newsletters about AISI project activities and attending show-andtell events. Perhaps not surprisingly, the general amount and nature of integrative parent involvement in schools remained largely unaffected by AISI (Parsons et al., 2006). One study of this phenomenon (Stelmach, 2004) described a school district that installed a special 'Action Team' to mobilize parents in AISI participation, by creating home-school linkages and active parental engagement in project strategies to improve learning. However the Action Team's discussions were kept separate from the teachers' curriculum meetings, and parents felt they were interfering inappropriately both with teachers' time and teachers' legitimate authority over classroom decisions.

As one parent suggested, 'I felt that we as parents didn't have as much to offer because, first of all we had to learn what the issues were.' When teachers came up with ideas, this parent admitted that the others on the Action Team agreed to go along with the teachers because parents and community members felt ill equipped to offer alternatives. In doing this, parents affirmed the cultural expectation that teachers are responsible for student learning. (Stelmach, 2004, para 34)

The translation of parents was limited to highly circumscribed roles in the network: receiving personal invitations to student award ceremonies and special newsletters about AISI progress, attending designated parent lunches and the like. Issues of persistent parental marginalization through social class, racialization and culture are not even recognized. Still, some parents participated, even in the awkward dialogues inviting parent suggestions that they sensed were unwelcome. Meanwhile, as Stelmach (2004) notes, the school entrance sign continued to regulate all visitors to report to the office, announcing clear insider-outsider boundaries and control of territory. Despite parents' apparent inscription as network participants in various AISI texts and attendances, they remained actors at the edges. Their partial translation recalls Nespor's (1994) warning about ANT's presumption of ever-expanding fluid networks: the social world of schools flows in very deep channels. 
What of the translation of teachers into actors in the AISI-network? According to a government AISI report, teachers have not only been converted into successful AISI researchers, but also into continuous learners focused on 'what works' orientation. In other words, the complex space and pedagogic flows comprising what it is to be a 'teacher' has been converted into measures of teaching capacity based on application of evidence-based practice: "Teachers now view themselves as learners and engage in inquiry related to the impact of their practices on student learning. They talk about gathering evidence of effective practices and use it to determine what works and what doesn't work for students" (Alberta Learning 2004, p. 48). However, in one of the only studies available that actually followed the actors in AISI, a more complex picture emerges. Mary-Lee Judah and George Richardson (2006) show how teachers they interviewed were both excited by the opportunity afforded by AISI to creatively develop new knowledge with their students and colleagues, and dismayed by the regulatory strictures and mandated involvement of the projects. In other words, teachers were "caught between competing discourses of personal empowerment and individual autonomy on the one hand and of the need to respond to externally driven measures of accountability and excellence on the other" (Judah and Richardson, 2006, p. 69). Teachers who were AISI coordinators, the study showed, also struggled in imposing projects on their colleagues that seemed to be highly regulated yet that offered potentially rich opportunity and time for professional learning.

Time itself became another space of complex enrolment. As AISI offered sufficient funds for substitutes to release teachers from classroom time, schools and districts could enable teacher gatherings for building curriculum and learning new strategy. For teachers, claim Parsons et al. (2006), this was an especially welcome space for new emergences. However, time away from the class occasion is not release from the class activity, as all teachers know who have labored late nights over substitute lesson plans for the next day of their absence. In AISI as with many educational implementations, teachers must maintain simultaneous presence in different forms and in different spaces that are not all delineated by the terms of the powerful network. Teachers inhabit life in their AISI enrolment as both researchers and as learners of teaching practice, in their ongoing classroom responsibilities as immanent engagement in that practice, in their regulated accounting to the government, and in their defense of boundaries defining their knowledge authority and practice - boundaries which AISI network strategies cannot re-inscribe and re-order despite continuing struggle so to do.

Not surprisingly, translation in educational reforms such as AISI is partial and diverse, representing ambivalent belongings rather than transformation and fluid spaces that escape network representation. Still, they are belongings, and the powerful AISI network in Alberta, like the IVC network in Central Queensland, has become durable as an extended set of connections among highly heterogeneous entities. Within and among these connections, however, are multiple openings and ungoverned regions where local, creative and unpredictable activity and identities can play.

\section{Conclusion}

Actor-network theory, as a diffuse array of analytic approaches, is argued here to afford fruitful questions for considering educational reform. In its conceptions of translations that link together heterogeneous materials, knowledges, emotions, agencies, bodies and technologies, ANT examines the micro-negotiations at these different links. It examines the ongoing work to enrol 
and mobilize all of these human and nonhuman elements into common practices and understandings that begin to resemble a stabilized 'network' of educational reform. In this sensibility, ANT readings ask, just how did this network come to extend itself? How did these varied entities come to be combined? What occurred at the various nodes and linkages to connect them? What kinds of connections are continuing to hold, why, and what else is working to hold them in place? What changes occurred in the process of these connections - and what didn't change? Where did resistance emerge and what happened to it? But beyond these questions are others, inspired by after-ANT readings (e.g. Law and Hassard, 1999). These questions strive to de-centre ANT's tendency to centrist, colonized network readings of all reality, and recall the otherness that happily escapes such obsessive tracing.

In terms of educational reform, the early kind of ANT analysis is useful to reveal the material interactions through which a major change initiative is successfully mobilized - even one that might be expected to inspire widespread critique and collective resistance among educators, such as mandated action research to create and measure evidence-based practice. The approach of tracing the moments of translation and strategies of ordering practices and identities helps illuminate how the change, conceptualized as a growing network, gradually extends and becomes durable. In effect, the network inscribes a new geography of social and material relations throughout an educational system. This analysis is particularly useful in tracing how ideas, practices and new technologies that appear to be completely foreign and irreconcilable with existing networks can eventually insinuate themselves as the new norms. This analysis can also examine the myriad wider connections implicated in educational reform. As Nespor (2002) asks, when the meanings of schools are connected to all sorts of things outside the border of the school, should not school change efforts address these relations?

However within this reading, we can see how translations vary: some entities are more peripherally enrolled, and some translations hold but are very leaky. The linkages often create ambivalent belongings, where people, things and collectives struggle to protect practices from inscription through these new connections at the same time as they work the connections for their own purposes. And we also see the other spaces that are non-calculable, and in fact not even representable by network logic. In the AISI network, local spaces allowed district and classroom project invention in directions that the network did not attempt to order - beyond allocating the space of design. These can be characterized as spaces within the network, held loosely between the ordering nodes. But other spaces also float alongside the network, unrecognized, uncaptured and unrelated to both its ordering processes and to the ANT researcher's network logic. These are the spaces of both ambivalence and of contradiction, where the direction and nature of action is undecidable and unpredictable. In these spaces, creative possibilities can emerge. However, they also can be contained and obscured through network strategies to block counter networks of invention.

The ANT-ish readings suggested here would trace not only the most visible movements of ordering in educational reforms, but also will gesture to the more elusive, more messy, more promising otherness of new possibilities. That is, attention to the socio-material connections and their patterns can discern not only closures but also openings in mass reform efforts, spaces for flux and instability embedded within and floating apart from the network. Most important, such readings can open inquiry into processes through which such possibilities can be protected and 
amplified, recognized, and perhaps connected together, where appropriate, to realize alternative educational change.

Alberta Education (2008) AISI Facts, Retrieved on October 202008 from http://education.alberta.ca/admin/aisi/about/whatisaisi.aspx

Alberta Learning (1999) Framework for the Alberta Initiative for School Improvement, Alberta Learning, Government of Alberta (Edmonton, AB, Alberta Education) .

Alberta Learning (2004) Improving Student Learning: Provincial Report for Cycle 1 (2000-2003), Retrieved on October 202008 from http://education.alberta.ca/media/325050/AnnReoprtFull_2001.pdf

Alberta Teachers Association (2008) Partnering for Success: the influence of AISI on Alberta's Faculties of Education, ATA Magazine, 85 (4). http://www.teachers.ab.ca/Quick\%20Links/Publications/Magazine/Volume\%2085/Numb er\%204/Articles/Pages/Partnering\%20for\%20Success.aspx

Burger, J., Aitken, A., Brandon, J., Klinck, P., McKinnon, G., \& Multch, S. (2001) The Next Generation of Basic Education Accountability in Alberta, Canada: a policy dialogue, International Electronic Journal For Leadership in Learning, 5:19, retrieved on October 202008 from http://www.ucalgary.ca/iejll/burger_aitken_brandon_klinck_mckinn on mutch

Bloomfield, B. and Vurdubakis, T. (1999) The Outer Limits: monsters, actor networks and the writing of displacement, Organization, 6: 4, 625-48.

Bowker, G.C. \& Star, S.L (2000) Sorting Things Out: classification and its consequences (Cambridge, MA, Ml T Press).

Busch, L. (1997) Actor Networks and the Division of Knowledge in the University, Paper presented at the annual meetings of the American Educational Research Association, Chicago, IL, pp. 1-7.

Callon M. (1986) Some Elements in a Sociology of Translation: domestication of the scallops and fishermen of St Brieuc Bay, in: J. Law (ed.), Action, Belief and Power (London, Routledge), 196-233.

Carson, T. \& Sumara, D.J. (Eds.) (1997) Action Research as a Living Practice (New York, Peter Lang).

Clarke, J. (2002) A New Kind of Symmetry: Actor-network theories and the new literacy studies, Studies in the Education of Adults, 34:2, 107-122.

Cochran-Smith, M. \& Lytle, S.L. (1999) The Teacher Research Movement: a decade 
later, Educational Researcher, 28: 7, 15-25

Crossan, M.M., Lane, H.W., \& White, R.E. (1999) An Organizational Learning Framework: from intuition to institution, Academy of Management Review, 24: 2, 522-537.

Czarniawska, B. \& Hernes, T. (2005) Constructing Macro Actors According to ANT, in: B.C zarniawska \& T. Hernes (eds.), Actor-Network Theory and Organizing, (Copenhagen, Liber and Copenhagen Business School Press), 7-14.

DuFour, R., \& Eaker, R. (1998) Professional Learning Communities at Work. (Alexandria, VA, Association for Supervision and Curriculum Development (ASCD).

Fenwick, T. \& Edwards, R. (2010 forthcoming) Actor Network Theory and Education (London, Routledge).

Fullan, M. (1993) Change Forces: probing the depth of educational reform (London, Routledge).

Hassard, J., Keleman, M. \& Wolfram-Cox, J. (2008) Disorganization Theory: explorations in alternative organizational analysis (London, Routledge).

Hassard, J., Law J. \& Lee, N. (1999) Introduction: actor-network theory and managerialism, Organization, 6: 3, 387-91.

Hetherington, K. \& Law, J. (2000) After networks: guest editorial. Environment and Planning D: Society and Space, 18, 127-132.

Judah, M-L \& Richardson, G.H. (2006) Between a Rock and a (Very) Hard Place: the ambiguous promise of action research in the context of state mandated teacher professional development, Action Research 4:1, 65-80.

Latour, B. (1996) Aramis, or the Love of Technology (Cambridge MA, Harvard University Press).

Law J. (1992). Notes on the Theory of the Actor Network: ordering, strategy and heterogeneity, Systematic Practice of Action Research 5:4, 579-593.

Law, J. (1999) After Ant: complexity, naming and topology, in: J. Hassard \& J. Law (eds.) Actor Network Theory and After (Oxford, Blackwell Publishers / The Sociological Review)

$1-14$.

Law J. (2003). Ordering and Obduracy, published by the Centre for Science Studies, Lancaster University, Lancaster LA1 4YN, UK, at http://www.comp.lancs.ac.uk/sociology/papers/Law-

Law, J. \& Hassard, J (Eds) (1999) Actor Network Theory and After (Oxford, Blackwell). 
Lee, N. and Brown, S. (1994) Otherness and the Actor-Network: the undiscovered continent, American Behavioural Scientist, 37: 6, 772-90.

Luck, J.T. (2008) Lost in Translations: a socio-technical study of interactive videoconferencing at an Australian university, Unpublished doctoral thesis, Central Queensland University, Australia.

MacEwan, N. (2008) AISI - Seven Years of Enthusiasm: improving learning and schools - innovation, renewal, sustainability, Alberta Learning, Government of Alberta (Edmonton, AB, Alberta Education) .

MacEwan, N. (2001) Improving Educational Performance in Alberta, Paper presented at the Conference on Empirical Issues in Canadian Education, Ottawa, Ontario, November 2001

McLean, C., \& Hassard, J. (2004) Symmetrical Absences/Symmetrical Absurdity: critical notes on the production of actor-network accounts, Journal of Management Studies 41: 3, 493-519.

Mol, A. \& Law, J. (1994). Regions, Networks and Fluids: anaemia and social topology, Social Studies of Science, 24, 641

Nespor, J. (1994). Knowledge in Motion: space, time and curriculum in undergraduate physics and management (London, Routledge).

Nespor, J. (2002) Networks and Contexts of Reform, Journal of Educational Change, 3: $365-382$.

Parsons, J., McRae, P., Taylor, L. with Larons, N. \& Servage, L. (2006) Celebrating School Improvement: six lessons learned from Alberta's AISI projects (Edmonton, Alberta, School Improvement Press).

Reeves, D.B. (2005, April) Execution: Transforming research into action, Presentation at the annual joint conference of the College of Alberta School Superintendents and Alberta Education, Edmonton, AB.

Stelmach, B. L. (2004) Unlocking the Schoolhouse Doors: institutional constraints on parent and community involvement in a school improvement initiative, Canadian Journal of Educational Administration and Policy, 31.

Taylor, A., Neu, N. \& Peters, F. (2002) Technocratic Control and Financial Governance: a case study of two school districts, Educational Management Administration Leadership, 469-499

Strathern, M. (1996) Cutting the Network, Journal of the Royal Anthropological Institute, 2, 517-35. 
Thrift, N. (2000) Afterwords, Environment and Planning D: Society and Space, 18, 213255.

Weick, K.E. \& Quinn, R.E. (1999) Organizational Change and Development, Annual Review of Psychology, 50, 361-86. 